\title{
Therapeutic effects of Sophora moorcroftiana alkaloids in combination with albendazole in mice experimentally infected with protoscolices of Echinococcus granulosus
}

X.M. Ma' ${ }^{1,2}$, G.SH. $\mathrm{Bao}^{2}$, J.M. Wan ${ }^{3}$, D.J. Liao, SH.F. Yin' ${ }^{2}$, X.Q. Meng ${ }^{1}$,

G.K. Zhou ${ }^{1}$, X.M. Lu ${ }^{5}$ and H.Y. Li ${ }^{1}$

\author{
${ }^{1}$ School of Life Sciences, ${ }^{2}$ School of Basic Medicine, Lanzhou University, \\ Lanzhou, Gansu, PR China \\ ${ }^{3}$ Department of Pharmacology, ${ }^{4}$ Department of Pathology, \\ Wayne State University School of Medicine, Detroit, MI, USA \\ ${ }^{5}$ Lanzhou Tongjian Biotechnology Company, Lanzhou, Gansu, PR China
}

Correspondence

\section{H.Y. Li}

School of Life Sciences

Lanzhou University

Lanzhou, Gansu

PR China

Fax: +86-931-891-2561

E-mail: lihy@|zu.edu.cn

..............................

Received November 6, 2006 Accepted July 2, 2007

\section{Abstract}

The objective of the present study was to determine if the combination of alkaloids from Sophora moorcroftiana seeds and albendazole might be effective in the treatment of experimental echinococcosis in female NIH mice (6 weeks old and weighing 18-20 g, N = 8 in each group) infected with protoscolices of Echinococcus granulosus. Viable protoscolices $\left(\mathrm{N}=6 \times 10^{3}\right)$ were cultured in vitro in 1640 medium and mortality was calculated daily. To determine the in vivo efficacy, mice were inoculated intraperitoneally with viable protoscolices and then treated once daily by gavage for three months with the alkaloids $\left(50 \mathrm{mg} \mathrm{kg}^{-1}\right.$ day $\left.^{-1}\right)$ and albendazole $\left(50 \mathrm{mg} \mathrm{kg}^{-1}\right.$ day $\left.^{-1}\right)$, separately and in combination (both alkaloids at $25 \mathrm{mg} \mathrm{kg}^{-1}$ day $^{-1}$ and albendazole at $\left.25 \mathrm{mg} \mathrm{kg}^{-1} \mathrm{day}^{-1}\right)$. Next, the hydatid cysts collected from the peritoneal cavity of the animals were weighed and serum IL-4, IL-2, and IgE levels were analyzed. Administration of alkaloids to cultured protoscolices showed significant dose- and time-dependent killing effects. The weight of hydatid cysts was significantly decreased upon treatment with each drug $(\mathrm{P}<0.01)$, but the decrease was more prominent and the rate of hydatid cyst growth inhibition was much higher $(76.1 \%)$ in the group receiving the combined treatments $(18.3$ $\pm 4.6 \mathrm{mg})$. IL-4 and total IgE were decreased $(939 \pm 447 \mathrm{pg} / \mathrm{mL}$ and $2.03 \pm 0.42 \mathrm{IU} / \mathrm{mL}$, respectively) in serum from mice treated with alkaloids and albendazole compared with the untreated control (1481 $\pm 619 \mathrm{pg} / \mathrm{mL}$ and $3.31 \pm 0.37 \mathrm{IU} / \mathrm{mL} ; \mathrm{P}<0.01)$. These results indicate that $S$. moorcroftiana alkaloids have protoscolicidal effects and the combination of alkaloids and albendazole has significant additive effects.
Key words

- Sophora moorcroftiana

- Echinococcus granulosus

- Alkaloids

- Cytokines

- Ethnobotany

- Therapeutics 


\section{Introduction}

Sophora moorcroftiana (Wall.) is a folk medicinal shrub endemic to the wide valleys and the middle reaches of several main tributaries of the Yalu Tsangbo River (Nianchu and Lhasa Rivers) in Tibet, China. The decoction of the seeds is used in Chinese folk medicine as an antiphlogistic, detoxicant, emetic, and in verminosis. Nine grams dried seeds, boiled in water, is commonly used in folk medicine to treat parasitosis $(1,2)$. Clinically, echinococcosis is most commonly treated with albendazole. However, albendazole is poorly absorbed in the intestinal tract and thus its hepatic concentration is low, a fact that reduces its efficacy since the liver is one of the organs most affected by echinococcosis. Patients with echinococcosis taking albendazole may have serious adverse reactions such as encephalitis syndrome, influenza-like syndrome, allergic purpura, drug rash, etc., and the treatment is not cost effective. Moreover, Echinococcus granulosus protoscolices have developed resistance to albendazole (3-7). Therefore, the search for new drugs continues. In the present study, we investigated the efficacy of the alkaloids extracted from S. moorcroftiana seeds, alone and in combination with albendazole, against cultured protoscolices and in the treatment of mice experimentally infected with protoscolices of Echinococcus granulosus. The results showed that alkaloids from $S$. moorcroftiana seeds combined with albendazole were highly effective against experimental echinococcosis.

\section{Material and Methods}

\section{Material}

Alkaloids (purity exceeding 90\%) were extracted from $S$. moorcroftiana seeds in our laboratory as described previously (8). Albendazole was purchased from Zhejiang Wanma Pharma Ltd. Co., Hangzhou, China.
MTT (3-[4,5 dimethylthiazol-2-yl] 2,5-diphenyltetrazolium bromide), dimethyl sulfoxide $\left(\mathrm{MeB}_{2 \mathrm{~B}} \mathrm{SO}\right)$, and RPMI medium 1640 were obtained from Sino-American Biotechnology Co., Shanghai, China, and the interleukin 4 (IL-4) radioimmunoassay kit was from Army General Hospital Technology Center, Beijing, China. IL-2 radioimmunoassay and IgE immunoradiometric assay kits were purchased from Beijing North Institute of Biotechnology, Beijing, China. S. moorcroftiana alkaloids and albendazole were diluted with $0.1 \% \mathrm{MeB}_{2 \mathrm{~B}} \mathrm{SO}$ to obtain the desired levels of concentration.

\section{Protoscolex collection and in vitro study}

Echinococcus granulosus protoscolices were aseptically removed from liver hydatid cysts obtained from sheep at the municipal abattoir in Qinghai Province, China. The protoscolices were washed several times with saline containing $100 \mathrm{kU} / \mathrm{L}$ benzylpenicillin and $100 \mathrm{mg} / \mathrm{L}$ streptomycin as described in the literature (9). The survival rate of the protoscolices exceeded $95 \%$ after these procedures. As described previously (7), $6 \times 10^{3}$ viable protoscolices were cultured in $5 \mathrm{~mL}$ RPMI 1640 medium supplemented with 100 $\mathrm{kU} / \mathrm{L}$ benzylpenicillin and $100 \mathrm{mg} / \mathrm{L}$ streptomycin. The alkaloids (0.75-6.0 g/L) and albendazole (T20 Tmg/L) were added separately $24 \mathrm{~h}$ later. Protoscolices cultured in a medium containing $0.1 \% \mathrm{Me}_{2} \mathrm{SO}$ served as the control. During the incubations, mortality was calculated daily by the methylene blue dye exclusion test (10). The experiment was repeated three times.

\section{Animal studies}

Normal inbred female NIH mice were purchased from the Lanzhou Institute of Biological Products, Chinese Ministry of Health, Lanzhou City, China. At 6 weeks of age (18$20 \mathrm{~g}$ in body weight), the mice were inoculated intraperitoneally with $2 \times 10^{3}$ viable 
protoscolices in $0.5 \mathrm{~mL}$ RPMI 1640 medium (11). The mice were housed under standard conditions with free access to food and water. After 30 days (12), the infected mice were divided into four groups of 8 mice each, and a group of 8 uninfected mice was included as control. All mice were treated by intragastric gavage with the alkaloids at 50 $\mathrm{mg} \mathrm{kg}{ }^{-1}$ day $^{-1}$, with albendazole at $50 \mathrm{mg} \mathrm{kg}^{-1}$ day $^{-1}$, and with both alkaloids $\left(25 \mathrm{mg} \mathrm{kg}^{-1}\right.$ day $\left.^{-1}\right)$ and albendazole $\left(25 \mathrm{mg} \mathrm{kg}^{-1} \mathrm{day}^{-1}\right)$, or with the same volume of distilled water containing $0.1 \% \mathrm{Me}_{2} \mathrm{SO}$ as the vehicle control. After 3-month treatments, the infected mice were anesthetized with pentobarbital sodium according to institutional guidelines, blood samples were collected from the ocular sinus, and the hydatid cysts were harvested from the peritoneal cavity. The weight of the hydatid cysts was measured immediately to examine the larval growth and the inhibition rate was calculated as described in the literature (13). The hydatid cysts were cut into pieces of about $1 \mathrm{~mm}^{3}$, fixed in $3 \%$ glutaraldehyde and $1 \%$ osmium tetroxide, dehydrated in graded alcohol, and embedded in epoxy resin. Ultrathin sections were doublestained with lead citrate/uranyl acetate before being examined with a JEM-100CX transmission electron microscope (JEOL Ltd., Tokyo, Japan) (14). Serum IL-4 and IL-2 were measured using monoclonal antibodies by radioimmunoassay and total $\mathrm{IgE}$ was measured using monoclonal antibodies by an immunoradiometric assay for the determination of therapeutic efficacy. Intraassay variations were $5 \%$ for $\mathrm{IgE}, 8 \%$ for IL-4, and $10 \%$ for IL-2. Interassay variations were $10 \%$ for IgE and $15 \%$ for IL-4 and IL-2. All assays were done at the same time.

\section{Statistical analysis}

Data are reported as means \pm SD. Statistical significance was determined by oneway ANOVA using the Statistical Package for the Social Sciences, version 10.0, for
Windows (SPSS Inc., Chicago, IL, USA).

\section{Results}

\section{In vitro treatment efficacy}

The mortality of E. granulosus protoscolices after exposure to different concentrations of alkaloids in culture is shown in Table 1. Although the untreated protoscolices showed increased mortality after a longer culture period, the mortality was only $29.1 \%$ by day 7 . Treatment with alkaloids induced a significantly higher mortality that increased with dose and treatment period, reaching $100 \%$ when alkaloids were given at $6 \mathrm{~g} / \mathrm{L}$ for 7 days. The efficacy at the lowest dose $(0.75$ $\mathrm{g} / \mathrm{L}$ ) was better than that of albendazole administered alone.

\section{In vivo treatment efficacy}

The in vivo efficacy was determined by measuring the weights of hydatid cysts from infected mice. Alkaloids alone at the dose of $50 \mathrm{mg} \mathrm{kg}^{-1}$ day $^{-1}$ significantly decreased the hydatid cyst weights compared with untreated mice, although the efficacy was still not as good as that of albendazole at the standard dose rate (50 $\mathrm{mg} \mathrm{kg}^{-1}$ day $^{-1}$; Table 2). Interestingly, combined treatment with alkaloids and albendazole showed some additive ef-

Table 1. Mortality of protoscolices treated in vitro with alkaloids for different periods of incubation.

\begin{tabular}{lcccc}
\hline \multirow{2}{*}{ Drug } & \multicolumn{4}{c}{ Mortality $(\%)$} \\
\cline { 2 - 5 } & 1 day & 3 days & 5 days & 7 days \\
\hline Untreated control & $2.1 \pm 1.1$ & $8.6 \pm 1.4$ & $14.6 \pm 3.3$ & $29.1 \pm 3.6$ \\
Alkaloids $(0.75 \mathrm{~g} / \mathrm{L})$ & $13.2 \pm 3.2^{*+}$ & $43.5 \pm 6.0^{*+}$ & $60.9 \pm 7.4^{*+}$ & $76.9 \pm 7.4^{*+}$ \\
Alkaloids $(1.50 \mathrm{~g} / \mathrm{L})$ & $17.0 \pm 3.1^{*+}$ & $62.2 \pm 6.7^{*+}$ & $78.3 \pm 8.9^{*+}$ & $95.2 \pm 8.8^{*+}$ \\
Alkaloids $(3.00 \mathrm{~g} / \mathrm{L})$ & $25.3 \pm 4.2^{*+\#}$ & $62.5 \pm 7.2^{*+}$ & $91.3 \pm 8.6^{*+\#}$ & $97.4 \pm 9.2^{*+}$ \\
Alkaloids $(6.00 \mathrm{~g} / \mathrm{L})$ & $33.5 \pm 5.6^{*+\#}$ & $66.7 \pm 8.4^{*+\#}$ & $93.8 \pm 8.8^{*+\#}$ & $100.0 \pm 0.0^{*+\#}$ \\
Albendazole $(0.02 \mathrm{~g} / \mathrm{L})$ & $12.4 \pm 2.7^{*}$ & $24.0 \pm 4.1^{*}$ & $36.7 \pm 5.5^{*}$ & $66.6 \pm 8.2^{*}$
\end{tabular}

Data are reported as means \pm SD for $6 \times 10^{3}$ viable protoscolices in each group. ${ }^{*} \mathrm{P}<0.05$ vs control; ${ }^{+} \mathrm{P}<0.05$ vs albendazole, and ${ }^{\#} \mathrm{P}<0.01$ vs alkaloids $(1.50 \mathrm{~g} / \mathrm{L})$ (one-way ANOVA). 
Table 2. Weight and inhibition rate of hydatid cysts and serum cytokine and IgE levels of mice.

\begin{tabular}{lccccc}
\hline Group & $\begin{array}{c}\text { Wet weight } \\
(\mathrm{mg})\end{array}$ & $\begin{array}{c}\text { Inhibition } \\
\text { rate }(\%)\end{array}$ & $\begin{array}{c}\mathrm{IL}-4 \\
(\mathrm{pg} / \mathrm{mL})\end{array}$ & $\begin{array}{c}\mathrm{IL}-2 \\
(\mathrm{ng} / \mathrm{mL})\end{array}$ & $\begin{array}{c}\mathrm{IgE} \\
(\mathrm{IU} / \mathrm{mL})\end{array}$ \\
\hline Blank & - & - & $477 \pm 297$ & $2.43 \pm 0.30$ & $1.99 \pm 0.37$ \\
Control & $76.6 \pm 12.0$ & 0.0 & $1481 \pm 619$ & $2.37 \pm 1.27$ & $3.31 \pm 0.37$ \\
Alkaloids & $48.3 \pm 9.0^{*}$ & 36.9 & $960 \pm 484^{*}$ & $1.96 \pm 0.42$ & $2.40 \pm 0.32^{*}$ \\
$\begin{array}{l}\text { Albendazole } \\
\text { Alkaloids }+ \\
\text { albendazole }\end{array}$ & $18.9 \pm 7.9^{*}$ & 64.9 & $976 \pm 628^{*}$ & $2.17 \pm 0.53$ & $2.68 \pm 0.28^{*}$ \\
& & 76.1 & $939 \pm 447^{*}$ & $1.80 \pm 0.40$ & $2.03 \pm 0.42^{*}$ \\
\hline
\end{tabular}

Data are reported as mean \pm SD for 8 animals in each group. Blank group was uninfected; control group was untreated; alkaloids group received alkaloids at $50 \mathrm{mg}$ $\mathrm{kg}^{-1}$ day $^{-1}$; albendazole group received albendazole at $50 \mathrm{mg} \mathrm{kg}^{-1}$ day-1, and alkaloids + albendazole group received both alkaloids $\left(25 \mathrm{mg} \mathrm{kg}^{-1}\right.$ day $\left.^{-1}\right)$ and albendazole (25 $\mathrm{mg} \mathrm{kg}^{-1}$ day $^{-1}$ ).

${ }^{*} \mathrm{P}<0.01$ vs control group (one-way ANOVA).

Figure 1. Electron micrographs showing the ultrastructure of hydatid cysts from untreated mice (A, 10,000X; B 26,000X) and from mice treated with alkaloids + albendazole at $50 \mathrm{mg} \mathrm{kg}^{-1}$ day $^{-1}$ (C, 13,000X; D, 12,000; E, $13,000 X)$. Hydatid cysts showed no changes in panels $A$ and $B$ (microtriches, arrows). In contrast, the hydatid cysts treated with alkaloids + albendazole showed loss of microtriches and numerous lipid droplets (a) in panel $\mathrm{C}$ together with accumulations of glycogen (b) and lysosomes (c) in panel D. The perinuclear space (d) was dilated and the cytoplasm of tegumental cells was vacuolated (e) in panel $\mathrm{C}$, the nuclei were broken into pieces (f) and pyknosis occurred (f) in panel $\mathrm{E}$.
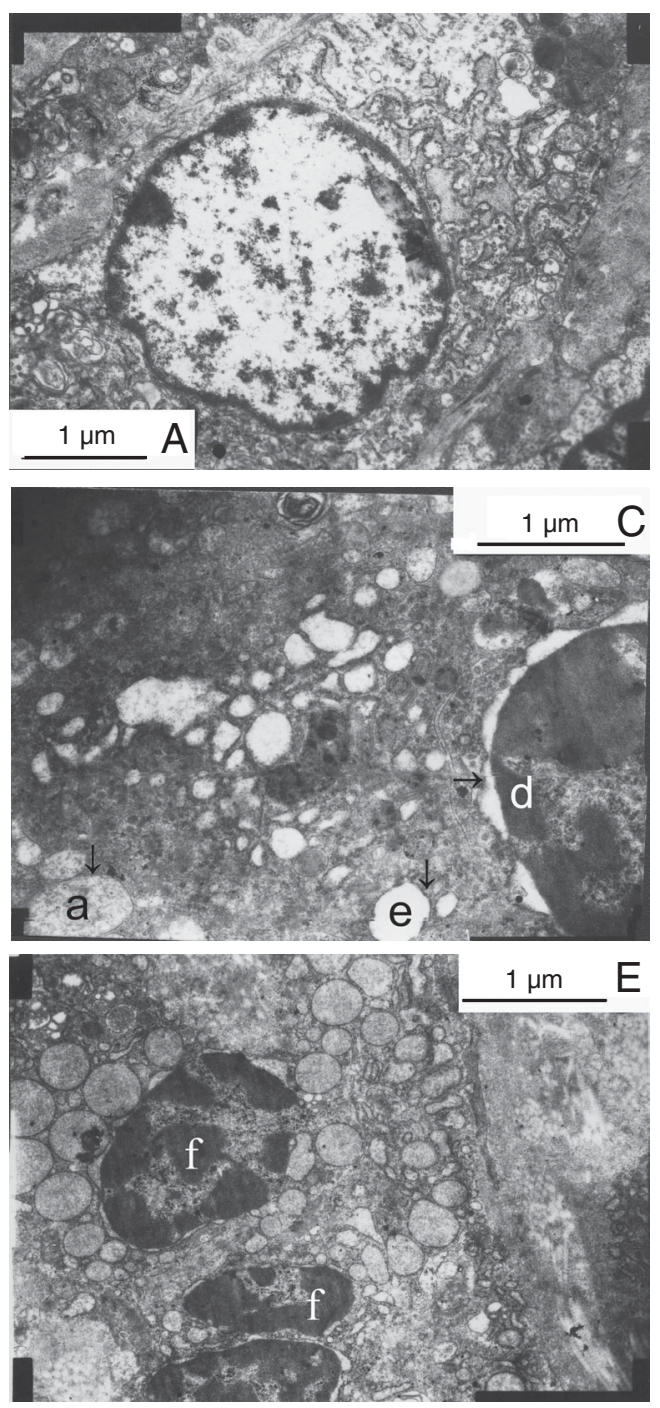

fects (Table 2). The number of cysts in the peritoneal cavity of the control mice was larger than that in the mice of all treated groups (data not shown). The cysts showed a hyaline aspect in the control group and were etiolated and opacified in all treated groups.

\section{Ultrastructural alterations}

The hydatid cysts present in the mice after 3 months of treatment did not show any changes in ultrastructure in the control group when observed by electron microscopy (Figure $1 \mathrm{~A}$ and $\mathrm{B}$ ). In contrast, the ultrastructure of the hydatid cysts from mice treated with alkaloids + albendazole $\left(25 \mathrm{mg} \mathrm{kg}^{-1}\right.$ day $^{-1}$ of
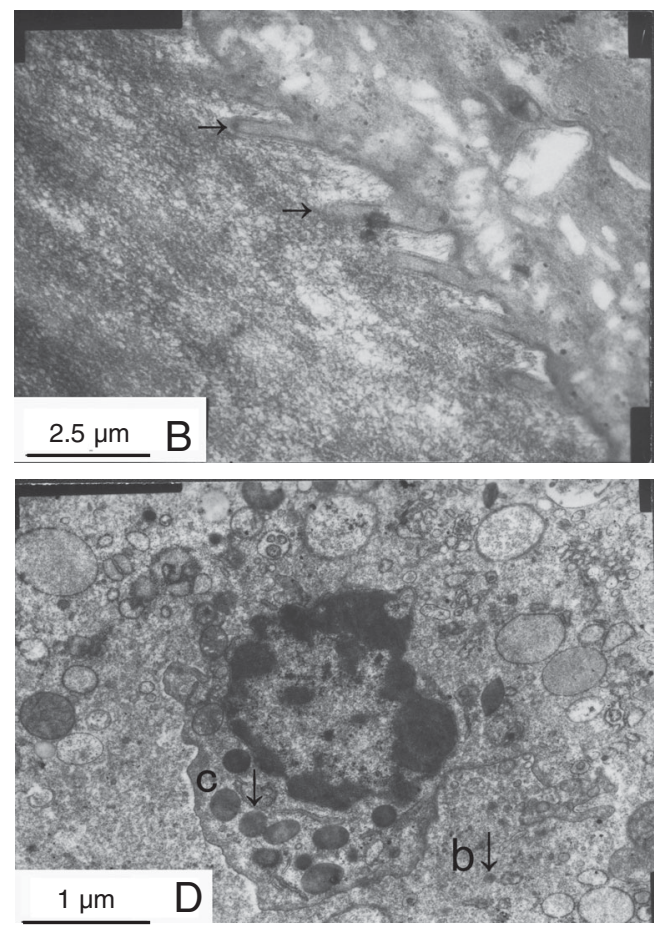
each drug) showed loss of microtriches in some areas and numerous lipid droplets (Figure 1C) together with accumulations of glycogen (Figure 1D) and lysosomes (Figure 1D) within the germinal layer. The perinuclear space was dilated in germinal layer cells (Figure 1C). The cytoplasm of tegumental cells was vacuolated (Figure 1C), the nuclei were broken into pieces and pyknosis occurred (Figure 1E). Loss of organelles was observed in the cytoplasm of germinal layer cells.

\section{Changes in cytokines}

As shown in Table 2, serum IL-4 and total IgE levels were decreased in mice treated with alkaloids or albendazole alone compared with untreated mice. Combined treatment with alkaloids and albendazole did not further reduce the levels of IL-4 and total IgE compared to treatment with each drug alone. IL-2 levels remained unaffected in all treated groups compared to the untreated control.

\section{Discussion}

Echinococcosis is a near-cosmopolitan zoonosis caused by adult or larval stages of cestodes belonging to the genus Echinococcus, which is widespread in western China (12). Clinically, echinococcosis is most commonly treated with albendazole. However, albendazole is poorly absorbed in the intestinal tract, attaining low levels of hepatic concentration and its high cost, serious adverse reactions, and resistance are limitations. Therefore, a search for new drugs is needed for the treatment of echinococcosis (3-7). In China, especially the Tibet areas, $S$. moorcroftiana seeds are commonly used for the treatment of verminosis $(1,2)$. We have previously extracted alkaloids, polysaccharides, and other components from S. moorcroftiana seeds and found that the alkaloids were the most effective components against protoscolices in vitro $(2,8)$. In the present study, we confirmed these findings and further showed, for the first time, that S. moorcroftiana alkaloids alone or in combination with albendazole have clear therapeutic effects on protoscolices in animals. Moreover, our results showed that the effect of the alkaloids could be observed as early as 1 day post-treatment, as is the case for albendazole. Treatment with albendazole required more than 5 days to increase the mortality rate of protoscolices to $36.7 \pm 5.5 \%$. After 3 days, the mortality of the protoscolices that had been incubated with alkaloids $(0.75 \mathrm{~g} / \mathrm{L})$ was $43.5 \pm 6.0 \%$. On the basis of these findings, it is probable that the effects of alkaloids on protoscolex mortality are both dose- and time-dependent.

The in vivo study showed that the combined treatment against echinococcosis in mice had a marked effect as indicated by reduced hydatid cyst weight and by structural cyst changes. Similar effects occurred when the two drugs, alkaloids and albendazole, were tested separately, but the efficacy of the alkaloids + albendazole treatment against hydatid cysts was greater than with either drug alone. S. moorcroftiana alkaloids alone or in combination with albendazole show a clearly detectable inhibitory effect on cyst development. In addition, we detected clear changes in the hydatid cysts after treatment with alkaloids + albendazole, such as the loss or destruction of microtriches, the appearance of numerous lipid droplets together with accumulations of glycogen and lysosomes, loss of organelles, breaking and pyknosis of nuclei in the germinal layer, which could be considered as indirect effects of the present treatment. Because the $\mathrm{LD}_{50}$ of alkaloids in mice is $207.81 \pm 20.80$ $\mathrm{mg} / \mathrm{kg}(8)$, this protoscolicidal effect may be related to the toxicity of alkaloids for hydatid cysts in vitro and for protoscolices in vivo.

Cytokines could play an important role in the host response to E. granulosus infec- 
tion. Examination of serum IL-4 and IgE levels in patients has been suggested to be helpful in monitoring the therapeutic effects $(13,15)$. In the present study, we found an obvious decrease of serum IL-4 and IgE levels in mice infected with protoscolices and then treated with the alkaloids for 3 months. It is possible that, after treatment, the growth of hydatid cysts may be inhibited and their structure destroyed; thus, the stimulation of cysts by immune cells is attenuated. Oxymatrine, oxysophocarpine, matrine, and sophocarpine were the only compounds successfully separated from the total alkaloids of $S$. moorcroftiana seeds (1). It remains to be seen whether the protoscolicidal action observed in vitro and in vivo was related to these isolated alkaloids or to other alkaloids yet to be separated from S. moorcroftiana seeds. Further studies on the isolation of the active principle and on its mechanism of action and safety are warranted to determine the feasibility of developing an effective drug for the treatment of echinococcosis.

\section{References}

1. Xingming $M$, Hongyu L, Shaofu $Y$, Xurging $M$, Gongke $Z H$, Xiaomin L. A study on bacteriostasis and inhibiting tumour cell proliferative activity of alkaloids from Sophora moorcroftiana seeds. J Lanzhou Univ 2003; 39: 74-77.

2. Xingming M, Hongyu L, Shaofu Y, Bo W. Apoptosis in SGC-7901 cells induced by alkaloids from Sophora moorcroftiana seeds. Chin Traditional Patent Med 2004; 26: 654-657.

3. Zhenguo $\mathrm{ZH}$, Xuezhi $\mathrm{Y}$, Yuanrong $\mathrm{ZH}$. Serious adverse reactions associated with albendazole. Chin J Pharmacovigilance 2005; 2: 7 10.

4. Guidelines for treatment of cystic and alveolar echinococcosis in humans. WHO Informal Working Group on Echinococcosis. Bull World Health Organ 1996; 74: 231-242.

5. Casado N, Urrea-Paris MA, Moreno MJ, Rodriguez-Caabeiro F. Combined praziquantel and albendazole chemoprophylaxis in experimental hydatidosis. Parasitol Res 2001; 87: 787-789.

6. Casado N, Moreno MJ, Urrea-Paris MA, Rodriguez-Caabeiro F. Could ivermectin have a synergic effect with albendazole in hydatidosis therapy? Parasitol Res 2002; 88: 153-159.

7. Urrea-Paris MA, Moreno MJ, Casado N, Rodriguez-Caabeiro F. In vitro effect of praziquantel and albendazole combination therapy on the larval stage of Echinococcus granulosus. Parasitol Res 2000; 86: 957-964.

8. Xingming $\mathrm{M}$, Hongyu $\mathrm{L}$, Shaofu $\mathrm{Y}, \mathrm{Bo} \mathrm{W}$. The study on bacteriostasis and anti-inflammatory activity of alkaloids from Sophora moorcroftiana seeds. Acta Chin Med Pharma 2004; 32: 23-25.

9. Urrea-Paris MA, Casado N, Moreno MJ, Rodriguez-Caabeiro F. Chemoprophylactic praziquantel treatment in experimental hydatidosis. Parasitol Res 2001; 87: 510-512.

10. Casado N, Rodriguez-Caabeiro F, Hernandez S. In vitro survival of Echinococcus granulosus protoscolices in several media, at $+4^{\circ} \mathrm{C}$ and $+37^{\circ} \mathrm{C}$. Z Parasitenkd 1986; 72: 273-278.

11. Urrea-Paris MA, Moreno MJ, Casado N, Rodriguez-Caabeiro F. Relationship between the efficacy of praziquantel treatment and the cystic differentiation in vivo of Echinococcus granulosus metacestode. Parasitol Res 2002; 88: 26-31.

12. Genshu B, Dazhong SH, Ying D. Study on growth inhibition of Echinococcus granulosus in mice and its mechanism of tetrandrine and albendazole. Endemic Dis Bull 2003; 18: 20-24.

13. Moreno MJ, Urrea-Paris MA, Casado N, Rodriguez-Caabeiro F. Praziquantel and albendazole in the combined treatment of experimental hydatid disease. Parasitol Res 2001; 87: 235-238.

14. Xingming M, Yanping L, Hongjuan $Y$, Yan C. Ethanolic extracts of Sophora moorcroftiana seeds induce apoptosis of human stomach cancer cell line SGC-7901 in vitro. Afr J Biotechnol 2006; 5: 16691674.

15. Torcal J, Navarro-Zorraquino M, Lozano R, Larrad L, Salinas JC, Ferrer $\mathrm{J}$, et al. Immune response and in vivo production of cytokines in patients with liver hydatidosis. Clin Exp Immunol 1996; 106: 317322. 